\title{
GIS-integrated rice irrigation management information system for a river-fed scheme
}

\begin{abstract}
The Tanjung Karang Irrigation Scheme is one of the large rice granaries in Malaysia. Irrigation management for rice irrigation is difficult because of different planting schedules, variability in soil and crop conditions and unreliable intake of water in the main canal due to the absence of storage reservoir and their uneven distribution to tertiary canals. In view of this concern, the scheme needs the daily estimation of the available water for irrigation and its equitable allocation among tertiary canals to cater trade-offs in water use for the scheme. Easy access of these spatially and temporally distributed data helps to make management system simpler. A GIS-integrated tool known as RIMIS was developed for equitable irrigation supply to tertiary canals and the characterization of their irrigation delivery performance as the season advances. RIMIS dynamically links a field irrigation demand prediction model for the area irrigated by a canal network in GIS. The system can correctly simulate and evaluate recommended irrigation supplies among tertiary canals that match the available discharge at the system head with the crop water demand for the actual field conditions. The user-interface was developed using ArcObjects and Visual Basic for Application (VBA) programming languages in ArcGIS software. RIMIS can give information on the uniformity of water distribution and the shortfall or excess and what decisions to adopt for the next day. It ensures equal sharing of water for the tail-end users. The system helps to keep input and output databases always updated with respect to the real field conditions. The results are displayed on the computer screen together with colour-coded maps, graphs and tables in a comprehensible form. This will help irrigation managers to enhance decision-making in the management and operation of the irrigation system. The development of the overall system and procedures is illustrated with data from a study area.
\end{abstract}

Keyword: Irrigation supply; Performance characterization; Tertiary canals; Rice; GIS 